DOI: $10.20472 /$ IAC.2017.031.006

\author{
SEMRA ATILGAN \\ MARMARA UNIVERSITY-FACULTY OF COMMUNATION, Turkey
}

\title{
A RESEARCH ON SOCIAL MEDIA USERS
}

\begin{abstract}
:
My study is based on social media users among young people especially university students. Social media users among university students are growing up recent years. Social media is the collective of online communications channels dedicated to community-based input, interaction, content-sharing and collaboration. Most of the students spend most of their times in social media. Some of them are - especially prominent- are facebook, twitter, Linkedln. So I decided to do a research this subject. I made a survey between university studensts and chose Marmara University - Faculty of Communication students. In this study enclose 270 women \% 64.2 and $150 \%$ 35.7 men students.
\end{abstract}

Surveys included in the study was carried out in sufficient number to achieve the data and make an overall assessment of various different multiple media students would be more appropriate due to be considered for research purposes. This study is limited by the number of measuring instruments used in the surveyed sample. Twelve questions asked to 420 students. Located on the continuous variables descriptive statistics in the study mean, standard deviation, median, minimum and maximum values of categorical variables are shown with frequencies and percentages. Compliance with the normal distribution of continuous variables was analyzed by Shapiro Wilk test. A comparison of the two groups Mann-Whitney $U$ test variable normal distribution, Kruskal-Wallis test used in the comparison group of three or more; For binary variables, the sub-group comparisons, a Bonferroni correction for meaningful Mann-Whitney $U$ test was used. All statistical analyzes value for comparison in the study below 0.05 was considered statistically significant. I will be glad to offer you this research results.

\section{Keywords:}

social media, students, survey 